Pilar Sánchez del Hoyo, Luis Javier Sanz Rodríguez

\title{
ABORDAJE PSICOTERAPÉUTICO EN HIJOS DE PADRES CON TRASTORNOS MENTALES GRAVES: A PROPÓSITO DE UN CASO
}

PSYCHOTERAPY APROACH FOR CHILDREN OF PARENTS WITH SERIOUS MENTAL DISORDERS: A CASE HISTORY

\section{RESUMEN}

Este trabajo tiene como objetivo profundizar en el estudio de los efectos que producen en el desarrollo infantil, la existencia de patología psiquiátrica en uno o ambos padres a través del recorrido de un caso clínico. Se presenta un caso de una menor de seis años que está siendo atendida en un Centro de Salud Mental, cuya madre padece un trastorno mental grave. Se defiende también la importancia de un abordaje o tratamiento preventivo que incida en el hijo y en el entorno familiar.

Palabras clave: Padres psicóticos, intervención familiar, desarrollo infantil, enfermedad mental grave.

\section{ABSTRACT}

This work aims to reflect in depth on the study of the influence of psychotic parents on child development through a review of a clinical study. We present the case of a six year old girl who is being treated in a Mental Health Center, whose mother suffers from a severe mental illness. We also defend the importance of a preventive approach or treatment that impinges on the child and family environment.

Key-words: Psychotic parents, family treatment, child development, severe mental illness. 


\section{INTRODUCCIÓN}

En diferentes publicaciones y estudios se ha mostrado que la existencia de trastornos psiquiátricos graves en los padres supone un riesgo en el desarrollo de los hijos y es más frecuente la existencia de patología mental en ellos que en la población infantil general (1).

La enfermedad mental severa está a menudo marcada por una incapacidad del sujeto para proveer del medio adecuado para el desarrollo del niño. Los niños que viven con madres esquizofrénicas o con trastornos afectivos mayores están en mayor riesgo de crianza inadecuada, patrones pobres de comunicación y caos ambiental (2).

D. W. Winnicott señala la importancia de la estabilidad y continuidad del medio, en sus aspectos físicos y emocionales, como necesarios para el desarrollo del niño y la etapa en la que se encuentra el menor, cuando aparece un factor traumático, para considerar el efecto de los padres psicóticos en los hijos (3). Spitz destaca la importancia de la relación madre-hijo. Las experiencias afectivas canalizan el curso del desarrollo de la personalidad y hacen posible la integración del proceso de maduración del infante. Las perturbaciones en la personalidad maternal reflejarán perturbaciones en el infante (4).

J. Bowlby, en su teoría del apego, destaca la importancia de la relación madrehijo para el desarrollo del menor. El apego se identifica con un interés insistente en mantener proximidad con una o unas pocas personas seleccionadas, la tendencia a usar a estos individuos como una base segura desde la cual explorar los entornos desconocidos y con la huida hacia esta figura de apego como refugio de seguridad en momentos de alarma. Para Bowlby el estado de seguridad, ansiedad o zozobra de un niño es determinado en gran medida por la accesibilidad y capacidad de respuesta de su principal figura de apego. Cuando existen separaciones prolongadas o repetidas, los niños atraviesan tres etapas de respuesta progresivamente más desfavorables, protesta, desesperación y finalmente, desconexión. La presencia de un familiar o figura sustituta estable, mitiga la inquietud, temor y el dolor provocado por la separación. Esto es muy importante en menores con uno o los dos progenitores con enfermedad mental, ya que en muchos casos existen otros familiares (abuelos, tíos, etc.) que colaboran en el cuidado y crianza del menor (5).

Mary Ainsworth clasifica la organización del apego en el niño hacia su padre/madre como seguro, evitativo y resistente/ambivalente. La organización segura está relacionada con la sensibilidad de la madre a las señales y comunicaciones del hijo, a la tendencia de ser rápida y reconfortante al responder al malestar y a una forma tierna y cuidadosa en el contacto físico con él. Estos niños suelen tener relaciones favorables con sus iguales y muestran escasa ansiedad en situaciones estresantes (6).

Según Ainsworth, algunos de los factores que influyen en la respuesta parental y que se observan en las madres de los niños con apego evitativo son la enfermedad familiar grave, relaciones infelices con el marido y presiones laborales abrumadoras. 
La evitación del niño está asociada al rechazo de la madre, tanto expresada indirectamente con comentarios indicando fastidio, como observada directamente en su aversión al contacto físico. Estos niños responden a las situaciones estresantes reprimiendo las expresiones de ansiedad y enfado.

La conducta ambivalente/resistente en el menor se relaciona con la insensibilidad materna hacia las señales del niño y, sobretodo a la impredecibilidad de respuesta, pero no con el rechazo de la madre. En situaciones estresantes son niños preocupados por la madre ante su ausencia y sin embargo, demasiado enfadados o angustiados como para reconfortarse con la vuelta de ésta.

Las madres con enfermedades mentales graves pueden tener dificultad en proporcionar los cuidados y apoyos necesarios y, sobretodo, en mantener la continuidad de dichos cuidados en momentos de crisis, pueden mostrarse rechazantes con sus hijos o con conductas impredecibles. Esto repercute en el desarrollo emocional de los niños, en sus patrones de comunicación y relación con los demás.

No obstante, algunos autores como Ainsworth o el propio Bowlby otorgan mucha importancia a la posibilidad de cambio en las relaciones tempranas y su efecto en el menor. Niños con un apego inseguro tienen el potencial de hacerse seguros cuando la relación con su madre mejora. Al mismo tiempo, algunos niños que están seguros durante su infancia tienen el riesgo de ser inseguros más adelante (7).

Existen numerosas publicaciones sobre el riesgo que corren los hijos de padres con trastornos mentales graves y su vulnerabilidad. Sin embargo, es difícil llegar a acuerdos en relación a las repercusiones, situaciones de riesgo y modelos de intervención. En el presente trabajo se presenta un caso que está siendo atendido en el Programa Infanto-juvenil de un Centro de Salud Mental, se trata de un menor cuya madre padece un trastorno mental grave.

\section{PRESENTACIÓN DEL CASO}

$\mathrm{N}$ es una niña de 5 años y 6 meses de edad que acude a consulta derivada por la psiquiatra que atiende a su madre, para valoración de tratamiento psicológico.

La primera entrevista se realiza con los padres. El padre no está muy de acuerdo con acudir a Salud Mental, no ve problemas en su hija, pero a medida que avanza la entrevista expresa que su hija tiene celos de la hermana, sabe que la madre está «malita» y cuando $\mathrm{N}$ se enfada se encierra en la habitación o dice que se va de casa. A la madre le preocupa que $\mathrm{N}$ no se interese por ciertas actividades en el colegio, se niega a hacer ciertas tareas, cuando ve mal o triste a su madre, le repite que la quiere mucho, dice también que son malos padres, se hace más pequeña y se encierra en su habitación durante horas, dice que ve monstruos y repite cosas que dice la madre. 


\section{EVALUACIÓN PSICOLÓGICA}

\section{Historia clínica}

1.1. Antecedentes personales y familiares

$\mathrm{N}$ no tiene antecedentes psiquiátricos ni psicológicos. La madre está en tratamiento psiquiátrico desde hace cinco años, al $4^{\circ}$ mes de edad de $\mathrm{N}$, «empecé a ver uñas y dientes en el bebé, pensaba que me intentaba matar, le he hecho daño, no creo que se acuerde», dice la madre. Es diagnosticada de trastorno de personalidad borderline con descompensaciones psicóticas.

Los padres han recibido apoyo en Servicios Sociales, en el programa específico de Familia e Infancia, durante tres años. El tratamiento se ha interrumpido hace tres meses, con el nacimiento de su $2^{\mathrm{a}}$ hija.

El padre consume alcohol en cantidades elevadas de forma esporádica y relacionada con etapas críticas o sentimientos de impotencia y soledad.

\subsection{Genograma}

El padre tiene 34 años, trabaja en una empresa desde hace 14 años. Está descontento con su trabajo, le exigen mucho y discute con sus jefes. La madre es ama de casa y tiene 35 años. Están casados hace 8 años. Para el padre es difícil entender la enfermedad de su mujer, a veces se pone furioso y discuten delante de la paciente. Tienen dos hijas de cinco y dos meses de edad respectivamente. La abuela materna vive largas temporadas con esta familia y ha sido una figura de apoyo importante, aunque la madre manifiesta ambivalencia afectiva hacia su propia madre y sentimientos de odio y dependencia.

El abuelo materno vive temporadas en el pueblo. Ha sido diagnosticado de cáncer de piel y le han intervenido quirúrgicamente en tres ocasiones. Tiene problemas bronquiales y es fumador y bebedor excesivo. De él dice la madre de N: «es irritable, se mete conmigo y con la educación de la niña. Nunca me ha tocado... ha pegado palizas tremendas a mi madre».

La abuela materna trabajó en un servicio de lavandería, donde sufrió una descarga eléctrica que le produjo quemaduras importantes cuando la madre de $\mathrm{N}$ era pequeña. Tuvo varios abortos, posiblemente provocados por el maltrato del marido. Actualmente su salud es muy precaria por un proceso de fibrosis pulmonar que padece. La madre de $\mathrm{N}$ la define como un poco insoportable.

La madre de $\mathrm{N}$ es la más pequeña de 8 hermanos. Mantiene buena relación con algunos de ellos. La $4^{a}$ hermana es la que cuidó de N. De ella dice: «le gusta jugar y beber en exceso, las dos cosas... se funde el dinero y nunca tiene un duro. Es con la que mejor relación tengo, le cuento las cosas que siento y que veo, y ella viene y me ayuda». 


\subsection{Datos evolutivos}

El embarazo fue deseado, el parto con cesárea, aspiró meconio y se realizaron dos lavados gástricos. Hubo lactancia materna en los primeros cuatro meses, vividos por la madre con gran temor a ser dañada por su propia hija: «a los pocos días de estar en casa, yo veía en la niña uñas largas y dientes, pensaba que me iba a hacer daño. Yo le daba el pecho, pero con miedo... yo me sentía sola... era como si lo rechazara y lo negaba... lo negaba, lo negaba... a veces temblaba mientras le daba el pecho... no dormía yo... como tenía uñas y dientes, estaba todo el rato mirando para que no me atacara... pensaba que era por venganza, por haber abortado cinco veces antes».

La madre acude al Servicio de Salud Mental al $4^{\circ}$ mes de edad de $\mathrm{N}$ y en un período de dos años tiene varios ingresos psiquiátricos, no puede ocuparse de la niña y esta labor de cuidados maternos la realizan una tía y la abuela materna hasta hace un año. El padre tampoco desempeña su función paterna. Por este motivo es difícil recoger información sobre el desarrollo de $\mathrm{N}$.

Una hermana de la madre se hace cargo del bebé hasta los dos años de edad. La madre dice: «se preocupaba por ella, le daba masajes, la bañaba...». Luego es la abuela materna quien se ocupa de $\mathrm{N}$ hasta los 4 años de edad. Existe desacuerdo entre los padres y la abuela en relación a las pautas de educación hacia N. La abuela no respeta lo que ellos dicen. La madre comenta: «la consiente demasiado, le pone telenovelas...».

En relación a la alimentación, tuvo cólicos del lactante. Actualmente come en el colegio por corregir ciertos hábitos caprichosos. No ha dormido sola en la habitación nunca, duerme en la misma habitación que la abuela, tiene dificultades para conciliar el sueño y precisa de la compañía de la abuela durante horas o de los padres. Le acuesta a las nueve de la noche y hay días que a las doce, la abuela todavía está contando cuentos. A la madre le cuesta abrazar o besar a su hija.

El inicio de deambulación es a los once meses de edad. Tiene un lenguaje claro a los dos años, controla esfínteres a los dos años también. Ha tenido un episodio de encopresis a los cinco años y cuando nació su hermana presentó enuresis $2^{\mathrm{a}}$ nocturna durante dos meses, que remitió espontáneamente. No ha padecido ninguna enfermedad importante.

Acudió a la guardería a los 4 meses de edad. La madre comenta que les dijeron que era una niña triste. Se escolarizó a los cuatro años y estudia $2^{\circ}$ de Educación Infantil y tiene dificultades con la lectura.

Sólo tiene una amiga en el colegio, no juega con otros niños, no les saluda cuando les encuentra en la calle y rehuye las relaciones, como lo hace su madre. Nunca ha jugado con muñecas ni otros juegos, solo escribe letras y palabras. No baja al parque a jugar.

El padre de $\mathrm{N}$ no ha ejercido la función de cuidador ni de figura de apego, no entendía la enfermedad de su mujer y delegaba dicha función en la abuela o tía materna.

Los comentarios de la madre acerca de su relación con $\mathrm{N}$ son: «ella ve más allá de la imagen que yo quiero dar... me siento muy unida a $\mathrm{N}$, porque tenemos cosas muy parecidas... pero veo en ella también las cosas malas que yo tengo... ella me pide que 
mejore... a gritos... pienso que no le hago el caso suficiente o la agobio, la persigo... estoy distanciada con ella, llevo mucho tiempo sin contarle cuentos... no la saco, no salgo a la calle, no salimos al parque... me encierro en la habitación todo el día...».

\section{Proceso de evaluación}

2.1. Entrevistas individuales

A N no le cuesta separarse de su madre y acepta bien los límites que se le ponen. En la primera entrevista se muestra nerviosa al principio, habla de forma desordenada, llena de palabras la entrevista sin responder a las preguntas que se le hacen, sabe que viene al médico. Se refiere a su hermana como la bebé, la pequeña. Algunos contenidos expresados son los siguientes: «lloro a veces cuando me pasa algo malo, me regañan y yo no he hecho nada... mamá a veces no se cómo se porta, eso no se cómo decírtelo... no se cómo se porta... a veces está bien...cuando tenía el bebé pequeñito en la tripa... antes lloraba más... hay cosas que es difícil decirlas». Se evade con otros contenidos y no quiere continuar hablando de lo que le preocupa.

Cuando finalizan las entrevistas, quiere llevarse los dibujos que hace, pero permite que los fotocopie. En sus relatos, en el juego o en sus dibujos aparecen contenidos relacionados con la muerte, (los padres están muertos, muere el abuelo o un pez que dibuja), le cuesta poner nombre a las princesas que dibuja (Figura 1), quizás porque pueden morirse también, y aparecen mecanismos de negación de la angustia y la tristeza, sobre todo en las primeras citas.

Figura 1

Dibujo de una princesa realizado por $\mathrm{N}$.

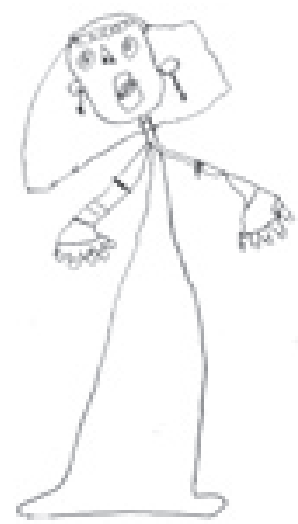

En el juego, le gusta jugar a las casas, coloca y organiza los cacharros, presenta cierto grado de perfeccionismo e insistencia en el orden. Posteriormente va introduciendo al terapeuta en el juego adjudicándole el papel de la madre a la que ella cuida, prepara la comida y hace regalos, buscando siempre el reconocimiento y la gratitud y ocupar un lugar privilegiado y único para la madre. Cuida también a la hermana menor. 


\subsection{Instrumentos de evaluación.}

Se ha aplicado la prueba del dibujo de la familia y el test de apercepción temática para niños (C.A.T.) $(8,9,10)$. Respecto a esta segunda prueba, las historias revelan a una niña de inteligencia sobre el promedio y verbalmente dotada, que muestra una adecuación a las percepciones típicas de las láminas, tanto con respecto a las personas, como a los otros elementos vistos. Los datos obtenidos por las respuestas de la paciente se hallan resumidos en la Tabla 1.

Tabla 1. Resumen de los resultados del CAT obtenidos por N.

\begin{tabular}{|c|c|c|c|c|c|}
\hline LÁMINA & 1 & 2 & 3 & 4 & 5 \\
\hline Tema principal & $\begin{array}{l}\text { Sometimiento a } \\
\text { figuras de } \\
\text { autoridad }\end{array}$ & Competencia & $\begin{array}{l}\text { Agresión } \\
\text { inintencionada } \\
\text { al padre }\end{array}$ & $\begin{array}{l}\text { Justificación } \\
\text { del error }\end{array}$ & $\begin{array}{c}\text { Sumisión a la } \\
\text { autoridad } \\
\text { paternal }\end{array}$ \\
\hline $\begin{array}{l}\text { Héroe } \\
\text { principal }\end{array}$ & Niño & $\begin{array}{c}\text { Niño pequeño } \\
\text { compitiendo con } \\
2 \text { niños mayores }\end{array}$ & Niño & Madre & Niños \\
\hline $\begin{array}{l}\text { Necesidades } \\
\text { e impulsos del } \\
\text { héroe }\end{array}$ & $\begin{array}{l}\text { Abatimiento, } \\
\text { Conflicto, niño } \\
\text { que tiene que } \\
\text { obedecer y hacer } \\
\text { algo que no le } \\
\text { gusta }\end{array}$ & $\begin{array}{l}\text { Disputa (agresión } \\
\text { emocional) } \\
\text { Dependencia } \\
\text { (recibe la ayuda } \\
\text { del adulto) }\end{array}$ & $\begin{array}{l}\text { Abatimiento, } \\
\text { Intraagresión } \\
\text { (culpa) }\end{array}$ & $\begin{array}{l}\text { Evitación de } \\
\text { culpa }\end{array}$ & Abatimiento \\
\hline $\begin{array}{l}\text { Concepto del } \\
\text { medio }\end{array}$ & $\begin{array}{c}\text { Inducción } \\
\text { (dominancia), } \\
\text { evitación de culpa }\end{array}$ & $\begin{array}{c}\text { Prohibición } \\
\text { (dominancia), } \\
\text { Alguien le ayuda } \\
\text { (modales) }\end{array}$ & $\begin{array}{l}\text { Rechazo, } \\
\text { Agresión social }\end{array}$ & $\begin{array}{l}\text { Agresión } \\
\text { social }\end{array}$ & Modales \\
\hline $\begin{array}{l}\text { Figura de } \\
\text { los padres } \\
\text { (masculina) }\end{array}$ & $\begin{array}{r}\text { Autoridad, } \\
\text { amistosa }\end{array}$ & Protectora & Le rechaza & Le culpa & $\begin{array}{l}\text { Autoridad, } \\
\text { amistosa }\end{array}$ \\
\hline $\begin{array}{l}\text { Naturaleza de las } \\
\text { ansiedades }\end{array}$ & Desaprobación & De carencia & De castigo & Desaprobación & $\begin{array}{c}\text { De ser } \\
\text { dominado }\end{array}$ \\
\hline $\begin{array}{l}\text { Mecanismos } \\
\text { de defensa }\end{array}$ & Racionalización & $\begin{array}{l}\text { Formación } \\
\text { reactiva }\end{array}$ & $\begin{array}{l}\text { Represión y } \\
\text { negación }\end{array}$ & $\begin{array}{l}\text { Represión y } \\
\text { negación }\end{array}$ & Aislamiento \\
\hline $\begin{array}{l}\text { Adecuación del } \\
\text { superyó (a través } \\
\text { del castigo) }\end{array}$ & Apropiado & Apropiado & $\begin{array}{l}\text { Demasiado } \\
\text { severo }\end{array}$ & Inconsistente & Apropiado \\
\hline $\begin{array}{l}\text { Integración del } \\
\text { Yo (a través del } \\
\text { argumento y } \\
\text { el final) }\end{array}$ & Incompleto & Feliz & Infeliz & Incompleto & Realista \\
\hline Inteligencia & \multicolumn{5}{|c|}{ Sobre el promedio } \\
\hline $\begin{array}{c}\text { Nivel de } \\
\text { maduración }\end{array}$ & \multicolumn{5}{|c|}{ Adecuado } \\
\hline
\end{tabular}




\begin{tabular}{|c|c|c|c|c|c|}
\hline LÁMINA & 6 & 7 & 8 & 9 & 10 \\
\hline Tema principal & Deprivación & $\begin{array}{l}\text { Agresión del } \\
\text { medio }\end{array}$ & $\begin{array}{l}\text { Ayuda de } \\
\text { un niño con } \\
\text { problemas }\end{array}$ & $\begin{array}{l}\text { Necesidad } \\
\text { económica }\end{array}$ & $\begin{array}{l}\text { Necesidad } \\
\text { económica }\end{array}$ \\
\hline $\begin{array}{c}\text { Héroe } \\
\text { principal }\end{array}$ & Niños & Niño & Niño & Niño & Niño \\
\hline $\begin{array}{l}\text { Necesidades } \\
\text { e impulsos del } \\
\text { héroe }\end{array}$ & Dependencia & Dependencia & Dependencia & Rendimiento & Rendimiento \\
\hline $\begin{array}{l}\text { Concepto del } \\
\text { medio }\end{array}$ & $\begin{array}{c}\text { Modales (el } \\
\text { adulto le ayuda) }\end{array}$ & $\begin{array}{c}\text { Peligro físico y } \\
\text { los padres } \\
\text { le salvan }\end{array}$ & $\begin{array}{l}\text { Modales (alguien } \\
\text { le protege) }\end{array}$ & $\begin{array}{c}\text { Inducción } \\
\text { (dominancia) }\end{array}$ & Rechazo \\
\hline $\begin{array}{l}\text { Figura de } \\
\text { los padres } \\
\text { (masculina) }\end{array}$ & Protectora & Protectora & Comprensiva & $\begin{array}{c}\text { Autoridad, } \\
\text { amistosa }\end{array}$ & Le rechaza \\
\hline $\begin{array}{l}\text { Naturaleza de } \\
\text { las ansiedades }\end{array}$ & De carencia & De daño físico & $\begin{array}{c}\text { De ser dominado } \\
\text { o indefenso }\end{array}$ & $\begin{array}{c}\text { De } \\
\text { desaprobación }\end{array}$ & \\
\hline $\begin{array}{c}\text { Mecanismos } \\
\text { de defensa }\end{array}$ & Simbolización & $\begin{array}{l}\text { Temor y } \\
\text { ansiedad }\end{array}$ & $\begin{array}{l}\text { Proyección e } \\
\text { introyección }\end{array}$ & $\begin{array}{l}\text { Proyección e } \\
\text { introyección }\end{array}$ & Aislamiento \\
\hline $\begin{array}{c}\text { Adecuación } \\
\text { del superyó } \\
\text { (a través del } \\
\text { castigo) }\end{array}$ & Apropiado & Apropiado & Apropiado & Apropiado & Apropiado \\
\hline $\begin{array}{l}\text { Integración del } \\
\text { Yo (a través del } \\
\text { argumento y } \\
\text { el final) }\end{array}$ & Feliz & Feliz & Feliz & Feliz & Feliz \\
\hline Inteligencia & \multicolumn{5}{|c|}{ Sobre el promedio } \\
\hline $\begin{array}{c}\text { Nivel de } \\
\text { maduración }\end{array}$ & \multicolumn{5}{|c|}{ Adecuado } \\
\hline
\end{tabular}

En general, la percepción del estímulo es buena, no apareciendo alteraciones importantes. Tampoco aparece una alteración formal del pensamiento. El lenguaje empleado es adecuado a la edad, bastante rico y exacto en cuanto a sus términos. 
De acuerdo con la recurrencia temática se plantean en orden de importancia las siguientes problemáticas: manejo de la agresión y la actitud hacia la figura de los padres y la manera en que estas figuras son apercibidas.

En cuanto a las soluciones planteadas ante estas dos problemáticas se encuentran dos posibilidades. En primer lugar, destaca el empleo de mecanismos de proyección e introyección, que se ponen de manifiesto con la aparición de conductas agresivas por parte del niño hacia el adulto. Finalmente, también se halla la represión y negación como mecanismos de defensa en situaciones en las que la agresión de la figura infantil reacciona con sumisión y aprende.

Respecto a la prueba del dibujo de la familia (Figura 2), se siguieron las pautas de aplicación e interpretación propuestas por Corman (11). En primer lugar, en cuanto al plano gráfico hay que destacar que $\mathrm{N}$ emplea un trazo fuerte y líneas amplias que ocupan buena parte de la página, lo que revela una gran expansión vital y una fácil extraversión de las tendencias.

Figura 2

Dibuio de la familia realizado por $\mathrm{N}$.

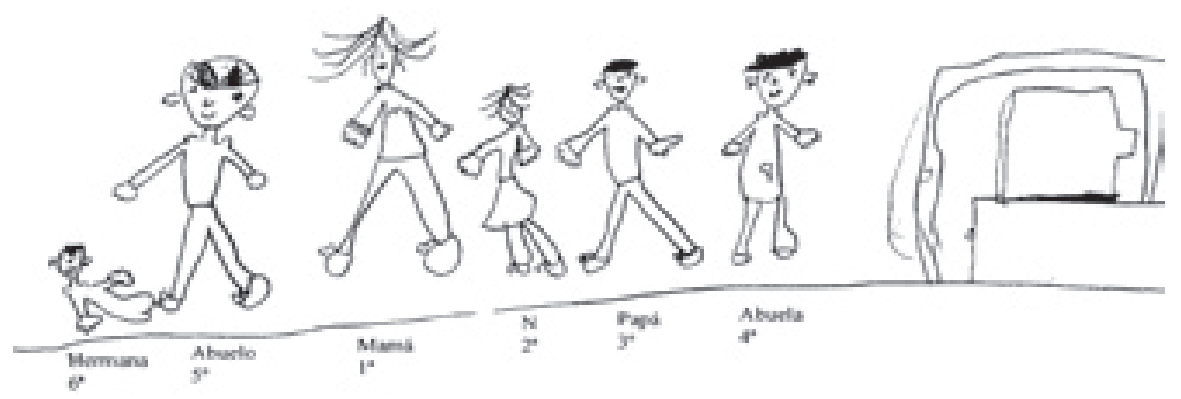

En segundo lugar, en el plano de las estructuras formales, el grado de perfección de las figuras señala una buena construcción de su propio esquema corporal para su edad, y la estructura del grupo resulta intermedia, con características sensoriales y racionales al mismo tiempo.

Finalmente, en el plano del contenido, surgen tendencias de amor y agresividad que se pueden ordenar mediante el conflicto infantil dominante en el dibujo de $\mathrm{N}$, la rivalidad fraterna. Aunque en su dibujo se expresa de forma indirecta cierto grado de agresividad hacia su hermana (siendo dibujada en último lugar y en un plano inferior al resto de los miembros de la familia), parece que esta rivalidad opera de manera natural y que el medio familiar es aparentemente armónico.

Hay una respuesta emocional de bloqueo cuando expresa quien es el menos feliz en esa familia. La menos feliz es ella y dice: «yo no soy feliz, porque me pasan muchas cosas raras». No accede a expresar qué cosas raras le ocurren. 


\section{JUICIO CLÍNICO}

Es una niña en situación de riesgo, su madre presenta una patología psiquiátrica que en períodos críticos le ha impedido acercarse afectivamente a su hija y ocuparse de ella. Teme ser agredida por su hija o que ésta haga daño a la hermana. El padre no ha realizado la labor de apoyo a la madre ni su función paterna adecuadamente, alejándose por su dificultad para comprender la enfermedad de su mujer y depositando en la tía y abuela maternas el lugar de figuras de apego.

$\mathrm{N}$ percibe el estado emocional de su madre, reaccionando ante ello. En el primer dibujo casi podríamos afirmar que dibuja el delirio de su madre, una princesa con uñas y dientes y en el juego, el contenido que repite es cuidar a la madre y la hermana y ofrecer una imagen buena de ella. Ella misma está incluida en el delirio de su madre en algunos momentos.

Presenta tristeza, preocupación, apatía, problemas de sueño, retraimiento y empobrecimiento en las relaciones sociales, no juega con otros niños salvo con una amiga y tampoco en su casa, no utiliza los juguetes que tiene, sólo pinta letras.

Se diagnostica como Trastorno de Vinculación en la infancia reactivo. F 94.1 C.I.E. 10 (12).

\section{TRATAMIENTO Y EVOLUCIÓN}

Esta familia está siendo atendida por los equipos de Salud Mental y Servicios Sociales. Existe coordinación entre ambos por ser una familia de riesgo y contar con ayuda domiciliaria.

Desde Salud Mental, la madre recibe tratamiento psiquiátrico y psicoterapéutico y es apoyada por la trabajadora social, que la recibe, a veces, con su madre.

Se realiza tratamiento psicológico con la niña a través del juego y dibujo y entrevistas con los padres. Estos últimos tienen una actitud colaboradora que va posibilitando cambios en la dinámica familiar. El padre participa más en el cuidado de las niñas, va asumiendo su función paterna. La madre es más afectiva con las hijas, se ocupa de ellas, aunque depende de su estado clínico, es capaz de besarlas y abrazarlas, facilita la relación con los iguales y la socialización y ejerce su papel de madre. Están empezando a jugar en la casa.

$\mathrm{N}$ ha normalizado sus conductas en el sueño, no necesita la presencia del adulto, come mejor y es más autónoma para vestirse, peinarse y comer. Reclama la atención de los padres como figuras de afecto y de referencia, no tanto a la abuela, aunque la presencia de ésta continúa siendo necesaria en los periodos críticos de la madre.

Se está trabajando para favorecer la socialización de las niñas, sobre todo de $\mathrm{N}$ que es más mayor, que acudan a ludotecas, asociaciones, actividades deportivas, etc., depositando en el padre la función de cuidado y facilitador de dichas actividades, implicándolo en el cuidado de las niñas. 
$\mathrm{N}$ utiliza el espacio terapéutico de juego como lugar donde reaparecen los conflictos afectivos y puede buscar la compensación de necesidades no satisfechas. No obstante, es una niña en situación de riesgo. Las etapas críticas de la madre influyen en la relación que establece con las hijas, sobre todo con la paciente, a la que percibe como mala y capaz de hacer daño. La afectividad de la madre se encuentra limitada así como su capacidad de realizar la función de cuidado, por lo que se hace necesario el apoyo del padre y la abuela materna. El padre tampoco es constante en el cuidado y afecto con las hijas.

Se mantiene el tratamiento de la madre, de la niña y con ambos padres, así como el seguimiento por parte de la trabajadora social.

\section{DISCUSIÓN}

Cuando se estudian los factores de riesgo para padecer problemas de salud mental en la infancia, los antecedentes familiares y sobretodo la existencia en uno o los dos progenitores de patología mental del tipo esquizofrenia u otras psicosis adquieren gran importancia (13).

Otro factor de riesgo es la existencia de funciones parentales empobrecidas, cuando padres y madres no pueden cuidar y educar a sus hijos con todas sus potencialidades debido a que se ven afectados por situaciones de trastorno mental, estrés, enfermedad física grave, marginación, ausencia, distancia emocional, etc. (14).

Winnicott destaca la importancia de la relación madre-hijo, que se inicia en los primeros momentos de la vida del niño, y diferencia los efectos de la psicosis en el padre y en la madre. Cuando se da en el padre, afecta menos en la temprana infancia de los hijos. La vida de estos se ve más alterada cuando la madre se encuentra en un estado caótico, el verdadero self no llega a formarse, se crea un falso self que intenta adaptarse a las dificultades con la que se encuentra. Estos niños pueden percibir el estado de ánimo de sus padres. Lo que les resulta más traumático es la imposibilidad de predecir cuál será la reacción de aquellos (15).

En muchos casos es el progenitor sano el que se aleja de los hijos, por proteger su propia cordura, por no entender la enfermedad o cómo poder afrontarla, y la responsabilidad recae en el progenitor enfermo. No es poco frecuente que en las separaciones de pareja, sea la madre, aún enferma, quien asuma el cuidado de los hijos y que sean ellas quienes soliciten ayuda para sus hijos y puedan colaborar, al menos en parte, en el tratamiento (16).

E. J. Anthony estudió el impacto en la vida familiar y las consecuencias en los hijos de la enfermedad grave en un progenitor. Los hijos pueden entender la enfermedad como una desorganización importante, como una crisis, como negligencia o como un reto en su vida. Es durante la adolescencia, especialmente, cuando pueden ir verbalizando sus sentimientos de angustia, culpa, vergüenza y lealtad (17). 
Dentro del programa de tratamiento con los menores que propone Anthony, son las intervenciones destinadas a desarrollar los recursos yoicos, a través de asociaciones, actividades lúdicas y deportivas, excursiones, etc. y las intervenciones en las fases agudas o recaídas de los padres, donde el menor puede hablar acerca de su experiencia de la enfermedad y de los sentimientos que le provoca, las que nos parecen más necesarias y útiles.

Por otro lado, para Rutter el daño proviene de la carencia o distorsión del cuidado, más que de la pérdida. Los trastornos mentales tienen un impacto mayor en el niño cuando este está incluido en la enfermedad del padre/madre, cuando es víctima de agresiones 0 está incluido en el delirio. La hostilidad, irritabilidad, las agresiones y violencia de los padres constituyen factores de riesgo más importantes que las manifestaciones psicóticas o los síntomas afectivos (18).

Para P. Bourdier, en el menor existe una necesidad de encontrar una explicación al comportamiento extraño del padre o madre. Lo esencial para la evolución del niño es la posibilidad que le ofrece o le niega la estructura familiar de tomar distancia con los trastornos del padre enfermo y de identificarse con imágenes sustitutorias positivas para él. Este autor describe a estos niños con apariencia de bien adaptados, hipermaduros. Sin embargo, esto no significa normalidad sino precocidad, sobreadaptación, hipercontrol, etc., lo que nos lleva a pensar en mecanismos de identificaciones masivas (19).

Lebovici destaca la importancia del desarrollo de programas preventivos, de trabajar con el progenitor enfermo, el menor y también con la familia. La madre psicótica puede dar a sus pequeños un afecto cálido pero irregular. En algunos casos la comunicación puede estar muy perturbada o el apoyo familiar no ser muy adecuado, de ahí la necesidad de servicios o programas que ayuden a la madre y a las familias (20).

Otra idea de partida es la que plantean White y cols. al plantear que los hijos que viven con madres con esquizofrenia o trastornos afectivos mayores tienen un mayor riego de vivir situaciones ambientales caóticas, patrones pobres de comunicación y crianza inadecuada. Proponen como aspectos fundamentales a tener en cuenta en el abordaje terapéutico: la información a la familia sobre la enfermedad y sus manifestaciones, mejorar los patrones de comunicación, disminuir el caos familiar y potenciar la competencia personal y social en los hijos (2).

Por último, es de reseñar el trabajo realizado por Dunn en el que recoge los recuerdos de la infancia de sujetos que crecieron con una madre psicótica. Estos niños han vivido experiencias de aislamiento en relación a sus iguales, su familia y la propia comunidad. La atención recibida por ambos padres es percibida como poco consistente, los padres son vistos como no disponibles ni física ni emocionalmente por ellos. En muchos casos acaban convirtiéndose en cuidadores de sus madres y hermanos pequeños, sin embargo nadie les habla de la enfermedad de sus madres 
y tienen sentimientos de culpa, fidelidad y lealtad hacia ellas, lo que dificulta su autonomía e independencia. Esta es una realidad muy frecuente cuando llegan a la adolescencia y juventud (21).

Sienten también humillación, vergüenza y confusión, al confrontarse con dos mundos diferentes, su realidad familiar y la realidad que viven en el entorno escolar y social. Estos menores buscan apoyo social, en muchos casos no dentro de la familia, sino en profesores, entrenadores, amigos de la familia, etc. ven a estas personas como elementos de seguridad y con disponibilidad para ellos, pero raramente les hablan de su situación familiar.

Finalmente, los contactos con Salud Mental en la infancia son vividos como evocadores de culpa y negativos, aunque en la edad adulta valoran la psicoterapia que reciben como positiva, en la que pueden verbalizar los miedos sobre su propia salud mental, explorar las relaciones con sus propias madres y establecer límites tanto físicos como afectivos con ellas.

Ante todas estas aportaciones queda claro que las necesidades de las figuras parentales con enfermedades mentales graves tienen mucho en común con las de otros padres. No obstante, existen una serie de áreas particulares que requieren cierta atención específica. En este trabajo se ha tratado de describir la problemática de los hijos de padres psicóticos, así como las implicaciones para la intervención en este campo, a través de un caso clínico. A lo largo del recorrido de este caso nos hemos encontrado con que las características específicas de esta población requieren tener en cuenta toda una serie de consideraciones preventivas, de apoyo y terapéuticas (22). A modo de conclusiones queremos destacar:

- La importancia de mantener la estabilidad y continuidad de los cuidados en la familia como situación favorable para el desarrollo del niño.

- La necesidad de tomar medidas preventivas en los casos donde hay un progenitor con una enfermedad grave.

- La conveniencia de proporcionar al niño información sobre la enfermedad de sus padres apropiada a su edad, para poder comprenderla como una realidad diferente a ellos, de la que no son causantes ni culpables.

- La necesidad de apoyo, soporte y tratamiento para los hijos destinado a desarrollar los recursos yoicos, a reforzar la confianza en sí mismos y proporcionar relaciones estables que permitan identificarse con imágenes sustitutivas positivas.

- La necesidad de incorporar al padre sano en el tratamiento y cuidado de sus hijos.

- La importancia del apoyo social y de otras figuras familiares y cercanas, contemplados como elementos de seguridad, atención y cuidado.

- La necesidad de desarrollar y utilizar servicios y recursos que ayuden a los padres psicóticos con sus hijos, tales como hospitales de día, guarderías especializadas y ayudas domiciliarias. 


\section{BIBLIOGRAFIA}

1. Bolívar Perálvarez, M., Vivas Guisado, J., Sanz de la Garza, C. «Hijos de padres con trastorno psiquiátrico». En: Gutiérrez Casares, J.R., y Rey Sánchez, F. (Eds.); Planificación terapéutica de los trastornos psiquiátricos del niño y del adolescente. Madrid, SmithKline Beecham, 2000.

2. White, C. I., Nicholson, J., Sher, W. H., Geller, J. I. «Mothers with Severe mental Illness caring for Children». Journal of Nervous and Mental Disease, 1995, 33, pp. 398-403.

3. Winnicott, D.W. El proceso de maduración en el niño. Estudios para una teoría del desarrollo emocional. Barcelona, Laia, 1981.

4. Spitz, R. El primer año de vida del niño. Madrid, Fondo de Cultura Económica, 1969.

5. Bowlby, J. La separación afectiva. Barcelona, Paidós, 1985.

6. Ainsworth, M. D. S. Patterns of attachment: A psychological study of the strange situation. Hillsdale, Erlbaum, 1978.

7. Fonagy, P. Teoría del Apego y Psicoanálisis. Barcelona, Espaxs, 2004.

8. Murray H. A., y Bellak, L. TAT, CAT-A y CAT-H. Tests de Apercepción Temática. Madrid, TEA Ediciones, 2001.

9. Bellak, L. El uso clínico de las pruebas psicológicas del T.A.T., C.A.T. y S.A.T. México D.F., Editorial El Manual Moderno, 1975.

10. Baringoltz, S. «Pautas de interpretación de apercepción infantil de L. Bellak». En: M. L. Siquier, M. E. García, y E. Grassano (eds.); Las técnicas proyectivas y el proceso psicodiagnóstico. Buenos Aires, Ediciones Nueva Visión, 1987.

11. Corman, L. El test del dibujo de la familia en la práctica médico-pedagógica. Buenos Aires, Kapelusz, 1992.

12. C.I.E. 10. Trastornos mentales y del comportamiento. Descripciones clínicas y pautas para el diagnóstico. Madrid, Meditor, 1992.

13. Jablenski, A. «Prevalence and incidence of schizophrenia spectrum disorders: implications for prevention». Australian and New Zeland Journal of Psychiatry, 2000, 34 (Suppl.), pp. S26-S34.

14. Artigue, J. y otros. «Una aproximación a la detección de los trastornos mentales graves». Revista de Psicopatología y Salud Mental del niño y el adolescente, 2004, 4, pp. 51-67.

15. Winnicott, D.W. La familia y el desarrollo del individuo. Buenos Aires, Ed. Hormé, 1980.

16. Hearly, J., y McGrath, J. «Motherhood and schizophrenia». En: D. J. Castle, J. McGrath, y J. Kulkarni (eds.); Women and schizophrenia. Cambridge, Cambridge University Press, 2000.

17. Anthony, E.J., Chiland, C. y Koupernik, C. L'enfant à haut risque psychiatrique. L'enfant dans sa famille. París, PUF, 1980. 
18. Rutter, M. «Maternal Deprivation Reconsidered». Journal of Psychosomatic Research, 1972, 16, pp. 241-250.

19. Bourdier, P. «L'hypermaduration des enfants de parents de malades mentaux». Rev. Franc. Psychan, 1972, 1, pp. 19-42.

20. Lebovici, S., Rabain-Lebovici, M. «Los niños de familias psicóticas». En: Tratado de Psiquiatría del Niño y del Adolescente. Tomo VI. Madrid, Biblioteca Nueva, 1989.

21. Dunn, B. «Growing up with a psychotic mother». A retrospective study. American Journal of Orthopsychiatric, 1993, 63, pp. 177-189.

22. Sánchez del Hoyo, P. y Sanz Rodríguez, L. J. «Hijos de padres psicóticos. Revisión bibliográfica: implicaciones preventivas, de apoyo y terapéuticas». Revista de Psicopatología y Salud Mental del niño y el adolescente, 2004, 4, pp. 99-107.

Pilar Sánchez del Hoyo

Psicóloga Clínica

Servicios de Salud Mental Parla (Madrid)

Luis Javier Sanz Rodríguez

Psicólogo Clínico

Servicios de Salud Mental del Área 10. Getafe y Parla (Madrid)

Servicios de Salud Mental de Parla (Madrid)

Correspondencia:

Luis Javier Sanz Rodríguez

C/Mayor, $232^{\circ} \mathrm{A}$

28891 Madrid 